\title{
SIGNIFICADOS DO SOUVENIR TURÍSTICO ATRIBUÍDOS PELOS TURISTAS DO PASSEIO DE TREM "MARIA FUMAÇA”, ESTAÇÃO DE BENTO GONÇALVES/RS
}

\begin{abstract}
MEANINGS ATTRIBUTED TO THE TOURIST SOUVENIR, BY VISITORS TO THE "MARIA FUMAÇA" TRAIN RIDE, BENTO GONÇALVES STATION/RS
\end{abstract}

\section{LOS SIGNIFICADOS DEL SOUVENIR TURÍSTICO ASIGNADOS POR LOS TURISTAS DEL PASEO EN TREN "MARIA FUMAÇA", ESTACIÓN DE BENTO GONÇALVES/RS}

Tauana Macedo de Paula

Mestranda do Programa de Pós-Graduação em Turismo e Hospitalidade Universidade de Caxias do Sul - UCS

tathamacedo@gmail.com

\section{Marlei Salete Mecca}

Docente do Programa de Pós-Graduação em Turismo e Hospitalidade Mestrado e Doutorado, Coordenadora e Professora do Curso de Ciências Contábeis - Universidade de Caxias do Sul - UCS

msmecca@gmail.com

Data de submissão: 26/10/2015

Data de aprovação:18/03/2016

RESUMO: O souvenir é um item predominante nas destinações turísticas. A teoria que o estuda traz que ele pode servir como um evocador das lembranças dos turistas, no momento em que os mesmos retornam à sua residência; também pode apresentar um caráter promocional da destinação à qual se refere; além de tangibilizar a experiência vivenciada. Ademais, os autores destacam que, geralmente, os turistas procuram souvenirs pequenos, que apresentem baixo valor monetário. No entanto, diante dos diferentes perfis de turistas existentes e das características contemporâneas, cabe questionar o que significa realmente o souvenir para estes turistas. Assim, o objetivo desta pesquisa é confrontar o que a teoria apresenta sobre souvenir, com a percepção dos turistas referente a tal 
elemento. Metodologicamente, este estudo de caso caracteriza-se por ser exploratório, com abordagem qualitativa. Para a obtenção dos dados, foram aplicados questionários no passeio de trem "Maria Fumaça"estação de Bento Gonçalves/RS. Dentre os principais resultados, identificaram-se algumas características do perfil do turista que frequenta esse atrativo; também se notou que este deseja encontrar produtos que caracterizem a região para, posteriormente, tornarem-se recursos de memória, confirmando as teorias confrontadas. A principal desmistificação desta pesquisa sinalizou que este turista está disposto a pagar um valor maior para consumir um produto característico da Serra Gaúcha.

PALAVRAS-CHAVE: Souvenir contemporâneo. Turista. "Maria Fumaça" - Bento Gonçalves/RS.

ABSTRACT: The souvenir is a predominant item in tourist destinations. The theory studied indicates that these items can serve to evoke tourists' memories when they return home; it can also act as a promotional tool of the destination, as well as making the experience more tangible. The authors point out that, generally, tourists look for small souvenirs with low monetary value. However, through the different profiles of tourists and contemporary features, it is worth asking what the souvenir really means for these tourists. The aim of this research is to compare what the theory says about souvenirs, with the tourists' perceptions of souvenirs. Methodologically, this case study is characterized as exploratory, with a qualitative approach. For the data collection, questionnaires were applied, relating to the "Maria Fumaça" train ride at Bento Gonçalves station/RS. Among the main results, some of the characteristics of tourists who visit this attraction were identified; it was also noted that tourists want to find products that characterize the region, which will later become memory resources, confirming the theories investigated. The main demystification of this research indicated that these tourists are willing to pay more for a characteristic product of the Serra Gaucha.

KEYWORDS: Contemporary souvenir. Tourist. "Maria Fumaça" - Bento Gonçalves station / RS.

RESUMEN: El souvenir es un elemento predominante en los destinos turísticos. La teoría que estudia el souvenir indica que puede servir como un evocador de recuerdos para los turistas cuando regresan a su hogar; también puede tener un carácter promocional del destino al que se refiere, así como hacer tangible la experiencia vivida. Por otra parte, los autores señalan que, en general, los turistas buscan pequeños recuerdos, que tienen bajo valor monetario. Sin embargo, teniendo en cuenta los diferentes perfiles de turistas y los elementos contemporáneos, vale la pena cuestionar lo que realmente significa el souvenir para estos turistas. El objetivo de esta investigación es confrontar la teoría presentada acerca del souvenir con la percepción de los turistas con respecto a ese elemento. Metodológicamente, este estudio de caso se caracteriza por ser exploratorio, con un enfoque cualitativo. Para obtener los datos se aplicaron cuestionarios sobre el paseo en tren "Maria Fumaça" - Estación de Bento Gonçalves/RS. Entre los principales resultados, se identificaron algunas características del perfil del turista que asiste a este atractivo; también se observó que los turistas quieren encontrar los productos que caracterizan a la región para, más tarde, convertirse en recursos de memoria, confirmando las teorías planteadas. La principal desmitificación de esta investigación indicó que este turista está dispuesto a pagar más para consumir un producto característico de la Sierra Gaucha.

PALABRAS CLAVE: Souvenir contemporáneo. Turista. "Maria Fumaça" - Estación de Bento Gonçalves / RS. 


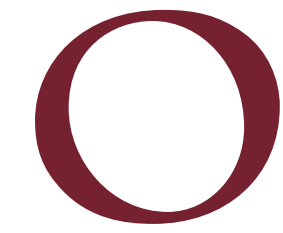

souvenir é um item inerente ao turismo, pois, na maioria das vezes, está presente nos atrativos turísticos, possibilitando seu consumo pelos turistas. Esses elementos fazem parte das experiências vivenciadas nas destinações turísticas, intensificando-as por meio da possibilidade de conhecer novas culturas e também as eternizando, de modo que o turista relembre posteriormente o que vivenciou no local.

Para alguns autores, o souvenir é uma forma de evocar recordações dos momentos vividos na viagem, tornando-se um recurso da memória (FREIRE-MEDEIROS; CASTRO, 2008; ESCALONA, 2006; SWANSON; HORRIDGE, 2004). Outros autores abordam a sua faceta promocional, quando o souvenir é oferecido como presente para amigos e/ou familiares, fazendo com que gere nestes a vontade de conhecer o local (NORRILD, 2004; HORODYSKI; MANOSSO; GÂNDARA, 2012; ESCALONA, 2006; SOUZA; CARVALHO, 2014, MELLO; CERETTA, 2015). Também existe a questão da tangibilização da experiência turística, tendo em vista que o setor de serviços caracteriza-se por ser abstrato (ESCALONA, 2006; RUBIO, 2006; SWANSON, 2004). Outras questões também são levantadas nas teorias sobre souvenir, como a atenção em criar um produto pequeno, barato e que possua em sua narrativa elementos que caracterizem e identifiquem o local visitado (GASTAL, 2004; ESCALONA, 2006).

De fato, estas características são as mais encontradas nos estudos elaborados sobre souvenir relacionado com o Turismo. Todavia, diante da diversidade de turistas existentes - podem-se citar os turistas de massa e os experienciais, além das características contemporâneas presentes, como a agilidade nas informações e nas comunicações e a valorização do simbólico -, cabe questionar as opiniões deste turista-consumidor contemporâneo sobre o souvenir.

Portanto: É possível pressupor que, atualmente, os turistas procuram souvenirs que primam pelas características locais, que sejam elaborados pela própria comunidade, de forma quase artesanal, retratando sua cultura e dispensando a produção em massa? E, ainda: Para este turista o valor monetário não deve ser motivo de preocupação, estando disposto a pagar uma quantia mais elevada por um produto, pois prioriza os aspectos já mencionados, além da qualidade? 
Como exemplificação dessa situação, pode-se citar o souvenir gastronômico: o vinho da Serra Gaúcha. Ou a preferência ainda é por objetos pequenos, com valor monetário baixo, não importando a sua origem; se realmente foi produzido na região onde o turista está vivenciando o turismo, ou se é um produto feito em larga escala importado de outros países.

Também são necessários questionamentos com relação à função do souvenir: São mesmo recursos da memória? Servem como presentes para aqueles que ficaram? Conseguem concretizar, de fato, as experiências vivenciadas na viagem?

Para isso é preciso confrontar as teorias com a realidade vivenciada pelos próprios turistas. Dessa forma, este artigo tem como objetivo principal apresentar o que os diversos autores, que abordam souvenir, apontam como função do mesmo, contrapondo-se com a percepção do turista-consumidor.

Para elucidar esse objetivo, foi elaborado um modelo de questionário misto, que foi distribuído na loja de souvenir do passeio de trem "Maria Fumaça", localizada na cidade de Bento Gonçalves, Serra Gaúcha, Brasil.

Sendo assim, após esta introdução, o artigo apresenta alguns aspectos sobre os perfis dos turistas; logo, a abordagem trata sobre o souvenir analisado sob a ótica da contemporaneidade; posteriormente, retratam-se os procedimentos metodológicos mostrando os caminhos desta pesquisa, bem como o seu campo de investigação; na sequência são realizadas as análises dos dados e, por fim, são apontadas as considerações finais e as referências utilizadas.

O TURISTA

Como mostrado na introdução, pelo menos dois tipos de turistas podem ser caracterizados, o turista de massa e o turista experiencial. Para Urry (2001), os turistas que estão dispostos a participar de um turismo de massa dificilmente terão contato com a comunidade local e serão inseridos em atrações inventadas com pouca autenticidade. Já os turistas que optarem por um turismo de experiência serão os protagonistas da sua viagem, tendo em vista que os mesmos viverão intensamente as sensações propostas pela destinação turística, não sendo expectadores passivos. (GAETA, 2010). 
De maneira pragmática, o turista pode ser definido como

(...) um visitante temporal que permanece ao menos 24 horas no destino e cujo propósito pode ser entretenimento (tempo livre), negócios, viagem familiar e reuniões. É a pessoa que está em viagem e que destina parte do seu tempo livre para atividades de recreação, entretenimento, lazer, enriquecimento cultural, entre outras. (PANOSSO NETTO, 2013, p. 52).

Ao longo das evoluções conceituais sobre turismo, surgiram algumas classificações destinadas aos turistas, principalmente entre as décadas de 70 e 80. Uma dessas classificações é a de Smith (1989), que distingue os turistas em sete perfis. O primeiro, é o explorador, que está aberto a conhecer novas culturas, acomodando-se facilmente no local. O segundo, é o turista de elite, que procura lugares ainda pouco visitados; suas viagens podem ser independentes e não programadas. O turista off-beat, terceiro da lista de Smith (1989), é aquele que procura afastar-se das multidões, optando por lugares mais reservados. $O$ quarto tipo de turista é o inusual, adepto a viagens pouco frequentes, ligadas à aventura e à emoção. O quinto perfil é o turista de massa incipiente, que viaja sozinho ou em pequenos grupos e procura por modernidades e diversão. O sexto tipo é o turista de massa pertencente, na maioria das vezes, à classe média e viaja a lugares conhecidos - caracterizados como a bolha turística. $O$ último modelo de turista é o charter, que costuma viajar em grupos pequenos com serviços padronizados.

Algumas dessas características apontadas por Smith, em 1989, ainda podem ser encontradas nos turistas de hoje. Todavia, diante da globalização, novas características foram agregadas à sociedade, que está cada vez mais envolvida em aportes tecnológicos característicos do século XX e em iniciativas criativas e culturais, apoiadas pelos conceitos de Economia Criativa, peculiares do século XXI. Assim, surgem novos perfis de turistas mais informados e ávidos por experiências turísticas menos padronizadas. Dessa forma, pode-se caracterizar esse turista segundo o quadro 1. 
Quadro 1 - Características dos turistas atuais

\begin{tabular}{|c|c|}
\hline & Síntese \\
\hline Indivíduo & $\begin{array}{c}\text { Deseja experiências mais personalizadas que atendam às suas necessidades e } \\
\text { expectativas e que o integre junto à comunidade local. }\end{array}$ \\
\hline Sociedade & $\begin{array}{l}\text { O turista pertence a um contexto social cuja particularidade está associada ao } \\
\text { instantâneo, à tecnologia, ao consumo, entre outros aspectos, que torna complexo } \\
\text { o mundo em que se vive hoje. }\end{array}$ \\
\hline Demografia & $\begin{array}{l}\text { A população mais velha está aumentando gradativamente, o que acarreta } \\
\text { uma porcentagem maior de turistas idosos, porém independentes intelectual } \\
\text { e financeiramente. Há, também, a questão da constituição familiar que está } \\
\text { caracterizada por menos pessoas, cada uma com gostos distintos. }\end{array}$ \\
\hline Estilo de vida & $\begin{array}{c}\text { As pessoas estão cada vez mais economicamente ativas e com seu tempo livre bem } \\
\text { definido. A disponibilidade de viagens está sendo um item de destaque em vagas } \\
\text { de emprego. Dessa forma, tornam-se mais corriqueiras as viagens de curto prazo } \\
\text { destinadas a negócios. }\end{array}$ \\
\hline Experiências & $\begin{array}{l}\text { Os turistas atuais possuem mais escolaridade, o que lhes proporciona um interesse } \\
\text { maior pelos locais visitados; ampliam sua capacidade de seleção e senso crítico. } \\
\text { Devido a isso, esses turistas primam mais pela qualidade. }\end{array}$ \\
\hline Valores & $\begin{array}{l}\text { O valor econômico das coisas não está sendo o principal elemento considerado. } \\
\text { O que está sendo prezado, agora, são as atividades ligadas ao meio ambiente, à } \\
\text { cultura, diversão, aventura e integração com os locais. }\end{array}$ \\
\hline Consumo & $\begin{array}{c}\text { Na hora do consumo, os turistas estão levando em consideração os aspectos } \\
\text { relacionados às emoções e à criatividade. }\end{array}$ \\
\hline Acesso & $\begin{array}{c}\text { Os turistas cobiçam maior acesso vinculado às informações sobre o local e as } \\
\text { experiências culturais. }\end{array}$ \\
\hline
\end{tabular}

Fonte: Elaboração própria baseada em Gaeta (2010).

Gastal (2004) corrobora algumas dessas informações, pois, segundo ela, o turista da contemporaneidade prioriza viagens em pequenos grupos, ou até mesmo sem companhia, além de valorizar as experiências pessoais conquistadas por meio do contato com a comunidade na qual está inserido. "Ou seja, este viajante quer construir seus próprios significados em relação aos lugares e às pessoas, buscando ultrapassar a caricatura e os estereótipos em relação às nacionalidades." (GASTAL, 2004, p. 12).

A identificação dessas e de outras características dos turistas pode ser conquistada por meio do marketing que sinaliza às empresas a importância de conhecer profundamente seu consumidor, pois assim as mesmas poderão atender melhor seus anseios. Esta estratégia é denominada "orientação voltada para o cliente", cuja base está alicerçada no domínio das características do consumidor (KOTLER; ARMSTRONG, 2007). No turismo também é fundamental 
que os segmentos (sol e praia, rural, cultural, religioso, aventura e os demais) preocupem-se em conhecer o seu turista, para ter condições de oferecer-lhe experiências que superem suas expectativas.

Nesta perspectiva, uma pesquisa realizada em 2012 pelo Serviço Brasileiro de Apoio à Micro e Pequenas Empresas (Sebrae), em parceria com a Confederação Nacional do Turismo (CNTur), com pessoas que viajaram pelo menos uma vez durante os últimos doze meses do ano em questão, aponta os possíveis perfis de turistas existentes nas Regiões Sul, Sudeste, Centro-Oeste, Nordeste e Norte do Brasil. Esse estudo não permite a generalização dos seus dados, porque foi elaborado mediante perspectiva qualitativa, por meio de grupos focais. No entanto, possibilita um conhecimento sobre algumas características dos turistas dessas regiões. Assim, o quadro 2 apresenta algumas informações relevantes dessa pesquisa.

Quadro 2 - Dados da pesquisa sobre o perfil de turistas do SEBRAE e da CNTur

\begin{tabular}{|c|c|}
\hline Tipo de turista & Considerações \\
\hline $\begin{array}{c}\text { Pessoas pertencentes às classes } \\
\text { B1 e B2, que tenham entre } 35 \text { e } \\
50 \text { anos e que sejam casadas e } \\
\text { com filhos }\end{array}$ & $\begin{array}{c}\text { A viagem para elas significa escapar da rotina } \\
\text { Desejam vivenciar novas experiências } \\
\text { Valorizam os aspectos intangíveis dos destinos turísticos } \\
\text { Geralmente viajam com a família ou amigos } \\
\text { Preferem viajar na baixa temporada para não enfrentar } \\
\text { aglomerações }\end{array}$ \\
\hline $\begin{array}{c}\text { Pessoas pertencentes às classes } \\
\text { B1 e B2, que tenham entre } 25 \text { e } \\
32 \text { anos e que sejam solteiras e } \\
\text { sem filhos }\end{array}$ & $\begin{array}{c}\text { Gostam de interagir com novas culturas } \\
\text { As viagens são uma oportunidade de renovação para a mente } \\
\text { Em alguns casos optam por viagens de curta duração } \\
\text { Priorizam o acesso fácil e rápido de informações sobre o destino } \\
\text { turístico } \\
\text { Valorizam a questão custo versus benefício. Querem pagar o preço } \\
\text { justo pelo que é oferecido }\end{array}$ \\
\hline $\begin{array}{l}\text { Pessoas pertencentes à classe } C \text {, } \\
\text { que tenham entre } 25 \text { e } 45 \text { anos }\end{array}$ & $\begin{array}{c}\text { Priorizam o planejamento financeiro antes da viagem } \\
\text { Os filhos têm grande poder de interferência principalmente pelo } \\
\text { acesso de informações via internet } \\
\text { As viagens são associadas às necessidades de descanso e lazer } \\
\text { Dão preferência a "pacotes" turísticos por acreditarem na sua } \\
\text { segurança e pela possibilidade do pagamento parcelado } \\
\text { No entanto, consideram negativas as programações intensas } \\
\text { proporcionadas pela maioria dos "pacotes" turísticos } \\
\text { Têm expectativas em desfrutar excelentes serviços }\end{array}$ \\
\hline
\end{tabular}




\begin{tabular}{|c|c|}
\hline Pessoas com mais de 55 anos & $\begin{array}{c}\text { O sinônimo das viagens para esse grupo é a valorização da vida } \\
\text { Buscam novidades } \\
\text { Valorizam os aspectos intangíveis } \\
\text { Desejam atenção e qualidade nos serviços } \\
\text { Querem respeito perante suas limitações físicas } \\
\text { Preferem viajar com amigos ou familiares } \\
\text { Buscam agências de viagens renomadas } \\
\text { Utilizam a internet como forma de obter informações sobre os } \\
\text { destinos turísticos e também para divulgar as suas experiências de } \\
\text { viagem via e-mail e redes sociais }\end{array}$ \\
\hline Pessoas entre 16 e 22 anos & $\begin{array}{c}\text { Relacionam a viagem com diversão } \\
\text { Buscam novas amizades } \\
\text { Possuem perfil aventureiro. Não se importam em viajar sem } \\
\text { planejamento prévio, desde que tenham companhia e recursos } \\
\text { financeiros } \\
\text { Valorizam as indicações da internet e de amigos } \\
\text { São pouco tolerantes com os erros de comunicação das empresas } \\
\text { do setor }\end{array}$ \\
\hline
\end{tabular}

Fonte: Elaboração própria baseada em pesquisa do Sebrae e da CNTur (2012).

É possível perceber nesta pesquisa o interesse pelos aspectos culturais intangíveis, como proporcionadores de novas experiências. Já a internet surge como uma das maiores divulgadoras de informações dos destinos turísticos; dessa forma, nota-se a necessidade de as iniciativas privada e pública estarem com seus dados atualizados na Web. As viagens em grupo foi outro item bastante mencionado na pesquisa, sinalizando a importância de serviços e atrações que atendam grupos distintos, desde a criança até o idoso. Outro destaque foi para a qualidade dos serviços, pois os participantes da pesquisa mostraram-se atentos a esta questão. Relacionando estes perfis com os propostos por Smith (1989), observa-se que ainda existe o turista de massa que opta por "pacotes" turísticos, que podem estar associados à "bolha turística" citada pela autora. Há também traços do turista explorador, que, segundo a mesma, se satisfaz conhecendo novas culturas.

Outro fato importante que deve ser analisado no perfil do turista é o seu consumo durante a viagem. Para Machado e Siqueira,

o consumo é uma espécie de mediação simbólica que se instaura entre o sujeito e o mundo possibilitando a construção de sentido a sua ação. Essa mediação, operada pela via simbólica, sobretudo, é significativa na construção de sentidos e significados de turistas em suas viagens pelas mais diferentes localidades. $(2008$, p. 3$)$. 
Segundo Swanson e Horridge (2004), uma das atividades preferidas dos turistas é comprar souvenir. O consumo destes elementos é repleto de significados, já que incluem tanto as singularidades de quem os produz como as de quem adquire (SOUZA; CARVALHO, 2014). De maneira geral, a aquisição do souvenir no destino turístico é importante, pois além de auxiliar na constituição da experiência turística, é uma forma de promover a localidade e, quando feito artesanalmente, contribui como fonte de renda para a comunidade local. "Em relação à atividade turística o consumo de souvenir marca a recordação do lugar visitado, a representação do produto local, sentimentos de pertencimento da comunidade visitada e a valorização da sua cultura." (MELLO; CERETTA, 2015, p. 189).

\section{O SOUVENIR NA CONTEMPORANEIDADE}

O souvenir é um elemento que está, na maioria das vezes, presente nas atividades turísticas. Pode-se dizer que ele serve como um evocador das lembranças da viagem. Dessa forma, esses itens concretizam a relação entre o lugar visitado e o lar para o qual se retorna (FREIRE-MEDEIROS; CASTRO, 2008). Assim, destaca-se o seu potencial de tangibilizar a experiência turística, pois essa, por se tratar de um serviço, possui características abstratas que poderão ser concretizadas por meio do souvenir (ESCALONA, 2006; RUBIO, 2006; SWANSON, 2004).

Em relação às origens do souvenir, sabe-se que esses elementos estão presentes nos deslocamentos humanos há muito tempo. Talvez não com a proposta que possuem hoje. Todavia algumas de suas características podem estar associadas ao modelo de souvenir contemporâneo. Os primeiros relatos que aparecem dizem respeito à era do Paleolítico Superior, em que foi constatado, por pesquisa do antropólogo Leroi Gouhran, que o ser humano já tinha o costume de coletar objetos (sem uma finalidade aparente) para exposição e exibição (RUBIO, 2006). Também há vestígios da aquisição de objetos nos deslocamentos dos egípcios e dos romanos (SWANSON; TIMOTHY, 2012). Escalona (2006) traz que, no período Medieval, os peregrinos que visitavam lugares considerados santos recolhiam algo (como recordação) para a vida futura. Já na época do Grand Tour, os souvenirs eram caracterizados por transmitir a cultura do local, 
por meio das antiguidades e das artes. Esses eram representados através de imagens gravadas de ruínas e de registros visuais da época, como vulcões, baías, vales e litorais feitos por artistas locais (SALGUEIRO, 2002). Quiçá, esta última seja a característica mais presente nas conceituações atuais sobre o souvenir.

Logo, para compreender a era contemporânea, é necessário entender primeiro a época anterior, a modernidade. Esta é caracterizada pela introdução da máquina e de seus desdobramentos, facilitando as atividades tanto na área urbana quanto na rural. Com isso, as distâncias, antes configuradas como longínquas, passam a ser percorridas em um curto espaço de tempo, devido aos avanços nos transportes. Já a contemporaneidade é marcada pela globalização, que diminuiu ainda mais as distâncias, graças ao advento da Tecnologia de Informação e Comunicação (TIC), que também altera a noção de tempo, já que a internet permite que a visualização de conteúdos seja em tempo real, ou seja, instantaneamente (GASTAL, 2005), não importando a sua localização geográfica.

Para Urry, a contemporaneidade, ou a pós-modernidade, como ele prefere,

(...) diz respeito a um sistema de signos ou símbolos, específico no tempo e no espaço. Tal sistema é caracterizável em termos de um regime específico de significações, no qual determinados objetos são produzidos, transmitidos e recebidos. Esses objetos envolvem um determinado conjunto de relações entre o significante, o significado e o referente. (2001, p. 119).

Dentrodessaótica, pode-seconsiderarestesobjetos, acrescidosdesignificados, como souvenir. Esse elemento, analisado sob o viés da contemporaneidade, está relacionado ao artesanato. Desenvolve-se em paralelo a este, tendo sua evolução atrelada, primeiramente, às miniaturas de peças originais; contudo, observa-se, cada vez mais, a sua independência e singularidade, tornando-se um elemento turístico (GASTAL, 2004). O modelo artesanal encontrado nos souvenirs de hoje apresenta características territoriais que valorizam a cultura de determinada comunidade, contribuindo, também, para o desenvolvimento local, por meio dos postos de trabalho proporcionados por esta produção.

Cabe destacar que ainda existem produções de souvenirs realizadas por meio de método industrial, que se caracteriza pela fabricação em massa, muitas vezes 
concretizadas em outros lugares, distantes daqueles aos quais faz referência. Contrapondo-se com a produção artesanal, esta acarreta um número maior de objetos e um custo monetário menor. Porém se salienta que esses souvenirs podem não ser originários do local onde o turista está no momento e, também, podem apresentar falsas narrativas, como no exemplo que Freire-Medeiros e Castro (2008) trazem sobre o Rio de Janeiro, no qual encontraram miniaturas de baianas representando a mulher carioca.

Outra característica contemporânea do souvenir é o seu papel promocional. Quando esse é oferecido como presente a um familiar ou amigo, pode fazer com que desperte nele o desejo de visitar tal local (NORRILD, 2004; HORODYSKI, MANOSSO; GÂNDARA, 2012). Torna-se, assim, uma estratégia de marketing. Mas para que isso de fato se concretize, não apresentando uma falsa narrativa, é importante que o produtor do souvenir conheça o local onde está inserido, incluindo os atrativos turísticos para, dessa forma, criar um produto, de acordo com as características locais (SWANSON; HORRIDGE, 2004). Diante disso, "é fundamental reconhecer e tornar reconhecíveis valores e qualidades locais" (KRUCKEN, 2009, p. 18).

Salienta-se ainda a relação de status social que o souvenir proporciona a quem o adquiriu, pois seu consumo serve como um confirmador da autenticidade da experiência vivida, auxiliando na ilustração sobre a cultura do local. Esses elementos identificam, diferenciam e posicionam o sujeito ao grupo social ao qual pertencem (REIS, 2008). "Permite a apropriação simbólica do lugar visitado, evidenciando a capacidade econômica de alcançar um desejo coletivo que não é possível para todos." (SCHLÜTER, 1998, p. 17).

Apesar da cultura pós-moderna impor uma globalização que, por meio das novas tecnologias, possibilita, como já dito, a diminuição das distâncias territoriais, criando também uma lógica de tempo diferente da época anterior, cuja preocupação, agora, está no futuro (GASTAL, 2004), observa-se que, paralelamente, há uma valorização e um desejo de preservação do saber-fazer tradicional (MELLO; CERETTA, 2015). Essas intenções, segundo Krucken (2009), visam a uma agregação de valor aos produtos locais, convertendo-se em um benefício sustentável para as comunidades. Nessa perspectiva, o souvenir 
artesanal, elaborado pela comunidade local por grupos que organizam o setor turístico, possibilitando o desenvolvimento regional, permite que a cultura genuína seja valorizada tanto pelos turistas quanto pelos autóctones, além de se tornar uma fonte de emprego e renda, agregando um valor maior aos hábitos locais (MELLO; CERETTA, 2015). O turismo é uma alternativa para integrar os produtos e os serviços locais em atividades que renovem a imagem da comunidade local, melhorando a vida de seus residentes, bem como atraindo turistas (KRUCKEN, 2009).

Tendo em vista estas características do souvenir contemporâneo, bem como os perfis de turistas mostrados, cabe a realização de um levantamento que esclareça o que o turista pretende encontrar em um souvenir: se, além dos aspectos de memória e concretização da experiência turística, o turistaconsumidor também valoriza os aspectos intangíveis (saber-fazer) da produção de um souvenir artesanal, ou se este define suas escolhas por objetos que possuam um valor monetário menor, não se atendo a sua procedência.

METODOLOGIA

Esta pesquisa empírica, caracterizada pela coleta de dados, pode ser definida, de acordo com o seu objetivo, como exploratória, na qual a finalidade principal centra-se no levantamento e na caracterização das variáveis pertinentes ao estudo (KÖCHE, 2013). Também foram utilizados métodos bibliográficos para a construção do referencial teórico que deu suporte à análise dos dados. Esse método desenvolve-se com base nos materiais já existentes sobre o tema (livros e artigos científicos, por exemplo) (GIL, 2007). Do ponto de vista dos procedimentos técnicos, foi utilizado estudo de caso. Pesquisas com esse tipo de processo são realizadas com um ou poucos objetos descrevendo-os, a partir das informações obtidas, com profundidade de detalhes (MASCARANHAS, 2012).

Quanto à abordagem do problema, este estudo é caracterizado como qualitativo. A análise qualitativa considera "a compreensão, a inteligibilidade dos fenômenos sociais e o significado e a intencionalidade que lhe atribuem os atores" (MINAYO; ASSIS; SOUZA, 2005, p. 82). A intenção desta abordagem não é comprovar suas informações numérica ou estatisticamente, mas sim na forma empírica, cuja análise é feita de forma detalhada e consistente (MICHEL, 2005). 
Com isso, a amostragem deste estudo foi definida como não probabilística, prevalecendo a amostra intencional que se compõe de sujeitos que possuem características estabelecidas. Corroborando a abordagem qualitativa, este tipo de amostra não permite a generalização dos dados, o que faz com que os mesmos tenham validade para um grupo específico (BARROS; LEHFELD, 2007).

Assim, foram disponibilizados questionários com questões mistas (abertas e fechadas) para turistas que adquiriram algum produto na loja de souvenir do passeio de trem "Maria Fumaça", localizada na estação de Bento GonçalvesRS. O instrumento ficou disponível no local, no período de 17 de julho a 31 de agosto de 2015.

Salienta-se, então, que a intenção da pesquisa não foi obter um grande número de respostas para serem analisadas estatisticamente, mas sim coletar os questionários que foram respondidos no período definido, a fim de avaliálos qualitativamente.

Com isso, as informações levantadas podem servir de base, para que novas pesquisas, com este mesmo perfil, sejam realizadas em outros locais e até mesmo para o aprofundamento desta em outra ocasião.

\section{BREVE CARACTERIZAÇÃO DO LOCAL DA PESQUISA}

Este estudo foi realizado na estação do atrativo turístico "Maria Fumaça", localizado na região nordeste do Rio Grande do Sul, mais precisamente na cidade de Bento Gonçalves (figura 1). Nessa região, predomina a colonização italiana, com a chegada de seus imigrantes entre os anos de 1880 e 1930. 
Figura 1 - Localização de Bento Gonçalves/RS

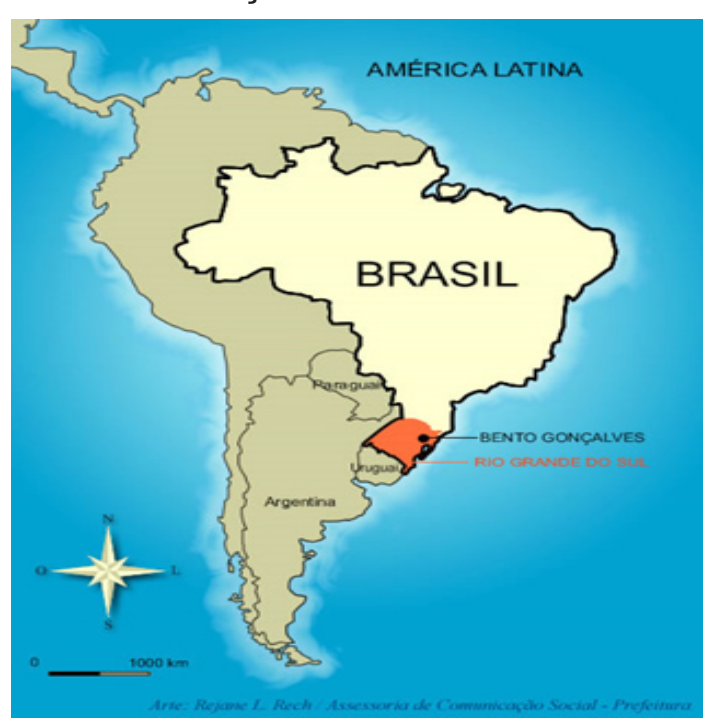

Fonte: Prefeitura Municipal de Bento Gonçalves/RS (2015).

O passeio de trem "Maria Fumaça" engloba três cidades: Bento Gonçalves, Garibaldi, Carlos Barbosa. O trajeto desse passeio possui 23 quilômetros, com uma duração média de duas horas. A sua operação fica sob a responsabilidade de uma empresa privada - Grupo Giordani Turismo - localizada no Município de Bento Gonçalves/RS (DEBENETTI, 2006).

A locomotiva utilizada no passeio data do século XIX, contando com seis carros (Figura 2). Seu funcionamento ocorre com o vapor produzido pela queima de lenha ou carvão mineral, em contato com a água (DEBENETTI, 2006). Cabe salientar que todo processo de utilização dos recursos naturais, bem como os cuidados com o entorno, é regulado pela norma técnica ISO 14001, responsável pela gestão ambiental.

Figura 2 - Locomotiva "Maria Fumaça"

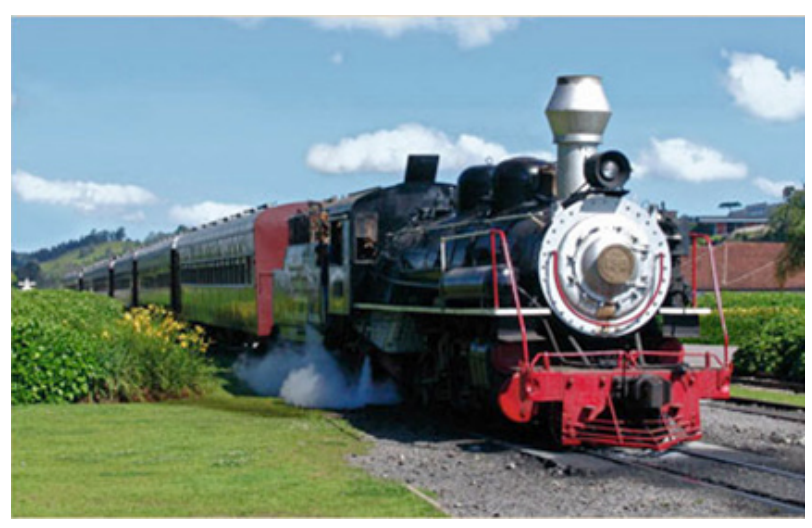

Fonte: Grupo Giordani Turismo (2015). 
Nesse passeio, os turistas têm a oportunidade de entrar em contato com a cultura italiana, por meio de manifestações artísticas e da gastronomia. Dentro da locomotiva, são realizadas apresentações como teatro e música. Nas estações de Bento Gonçalves e Garibaldi, são proporcionadas degustações de produtos da região, como vinho, queijo e champanha (DEBENETTI, 2006). Em Carlos Barbosa, os turistas são recebidos com música italiana interpretada por artistas locais.

Na loja de souvenirs do passeio de trem "Maria Fumaça", onde foi realizada a pesquisa, encontram-se diversos produtos caracterizados como artesanato, representados por cuias para chimarrão, porta-garrafas de vinho, bolsas de dressa (feitas com palha de trigo), entre outros; vestuário constituído por roupas feitas em tricô e crochê, boinas e blusas; alimentos compostos por doces diversos, biscoitos e bebidas; réplicas que envolvem miniaturas do trem "Maria Fumaça" e de Santo Antônio (padroeiro de Bento Gonçalves/RS); produtos que contêm a marca local, formados por ímãs de geladeira, chaveiros, entre outros (PAULA; MECCA, 2015).

\section{ANÁLISE DOS DADOS}

Osquestionamentos dapesquisa pretenderamapontaralgumascaracterísticas do perfil do turista que comprou souvenir na loja do passeio de trem "Maria Fumaça", mediante perguntas, tais como: idade, gênero, escolaridade, renda e cidade/estado de origem. Na sequência, as indagações versavam sobre o souvenir, com o objetivo de identificar a motivação do turista na aquisição do mesmo. Para isso, os pontos levantados foram: O produto comprado pode ser caracterizado como um souvenir? Por quais motivos o produto foi comprado? 0 que o turista espera encontrar no produto adquirido? O produto comprado pode auxiliar nas lembranças da viagem? A importância do souvenir estava associada à cultura local? O produto comprado complementa a experiência turística? Quais produtos foram adquiridos? Quanto foi investido nos mesmos?

Em relação ao perfil dos turistas, contatou-se que $60 \%$ representam o gênero feminino. Já no quesito idade, o público jovem, de 20 a 30 anos, 
foi o que predominou na pesquisa, totalizando $40 \%$ das respostas. Sobre a escolaridade, constatou-se que a maioria dos respondentes possui Ensino Superior incompleto (30\%). No que diz respeito à renda, verificou-se que a maioria dos questionados possui uma renda entre dois a dez salários-mínimos $(R \$ 1.576,00$ até $R \$ 7.880,00)$, totalizando $60 \%$ das respostas. Sobre a origem dos turistas, observou-se que, apesar de aparecerem turistas de outros estados do Brasil, a maioria dos participantes é do Rio Grande do Sul (gráfico 1), mais precisamente das cidades de Porto Alegre, Bento Gonçalves e Garibaldi.

Gráfico 1 - Cidade e estado de origem dos participantes da pesquisa

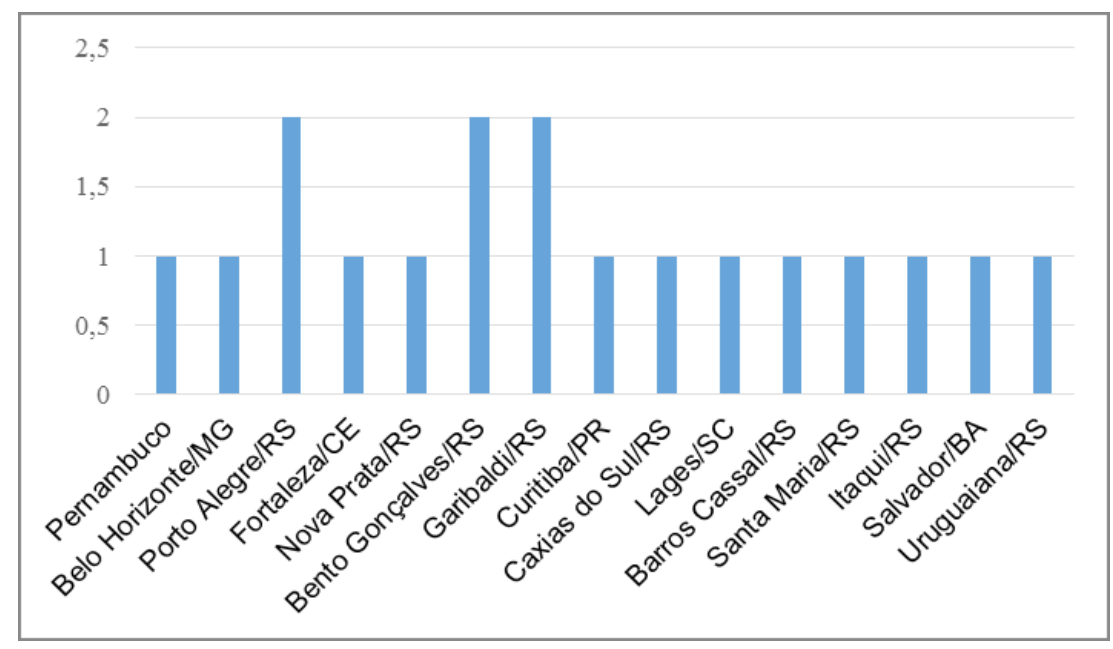

Fonte: Elaboração própria.

Esta caracterização do turista-consumidor que frequenta a loja de souvenirs do passeio de trem "Maria Fumaça" torna-se importante tendo em vista que, a partir desta ação, é possível se ater às especificações deste público. Como apresentado, o gênero feminino predominou nesta pesquisa, seguida por uma faixa etária de jovens entre 20 a 30 anos que, segundo a pesquisa do Sebrae e da CNTur (2012), esses jovens procuram viagens que os coloquem em contato com outras culturas; que priorizem o acesso rápido sobre as informações do local, entre outras características. A escolaridade da maioria dos respondentes supõe que eles estão procurando se qualificar em uma área específica no Ensino Superior. Segundo Gaeta (2010), essa particularidade Ihes proporciona maior interesse pela cultura local, devido à sua capacidade de senso crítico, além de priorizarem a qualidade. Em relação à origem dos turistas, observa-se que os gaúchos se destacam na pesquisa, inclusive os moradores do entorno do passeio 
- Bento Gonçalves e Garibaldi -, o que significa que a própria comunidade local está valorizando sua cultura.

A relação dos próprios moradores, de usufruírem do atrativo turístico da região, como no caso dos cidadãos de Bento Gonçalves, abre espaço para outro tipo de turista que está sendo cada vez mais foco de estudos: o turistacidadão. Este "[...] vivencia, usufrui e experiencia as paisagens de sua própria cidade durante o seu tempo livre" (MELO; DIAS, 2014, p. 10). O turismocidadão possibilita o estreitamento da relação entre o morador e sua cidade, promovendo o sentimento de pertencimento e a valorização da sua identidade. Ainda gera nesse indivíduo a vontade de conhecer um pouco mais sua cultura e, por consequência, a preocupação em preservá-la (MELO; DIAS, 2014).

Em relação ao souvenir, observa-se que $75 \%$ dos questionários respondidos consideram o produto comprado com um souvenir uma "lembrança do local visitado". Dessa forma, nota-se que a maioria dos turistas considera o produto adquirido como um item que irá auxiliá-los no momento em que forem se recordar da viagem.

Quando perguntado por qual motivo o turista comprou o produto, a maior parte dos questionados apontaram que o mesmo caracteriza a cultura da região. Esse ato pode ser associado à necessidade de resgatar a cultura e as tradições de um povo, característica da contemporaneidade. Seguida da questão de que este item os ajudaria a se lembrar dos momentos vividos na viagem, e corrobora a primeira indagação e os referenciais que trabalham com a máxima de que o souvenir pode ser um facilitador da memória humana. Em terceiro lugar, aparece a compra do souvenir para presentear alguém, o que acarreta a divulgação do destino, como mostrado na teoria (gráfico 2). "O que há de belo nos souvenirs é que eles nos abrem as portas da imaginação e a todo tipo de associações mentais, estimulam discursos tangenciais e nos reenviam a várias disciplinas e correntes do pensamento." (RUBIO, 2006, p. 280). 
Gráfico 2 - Por quais motivos você comprou este produto

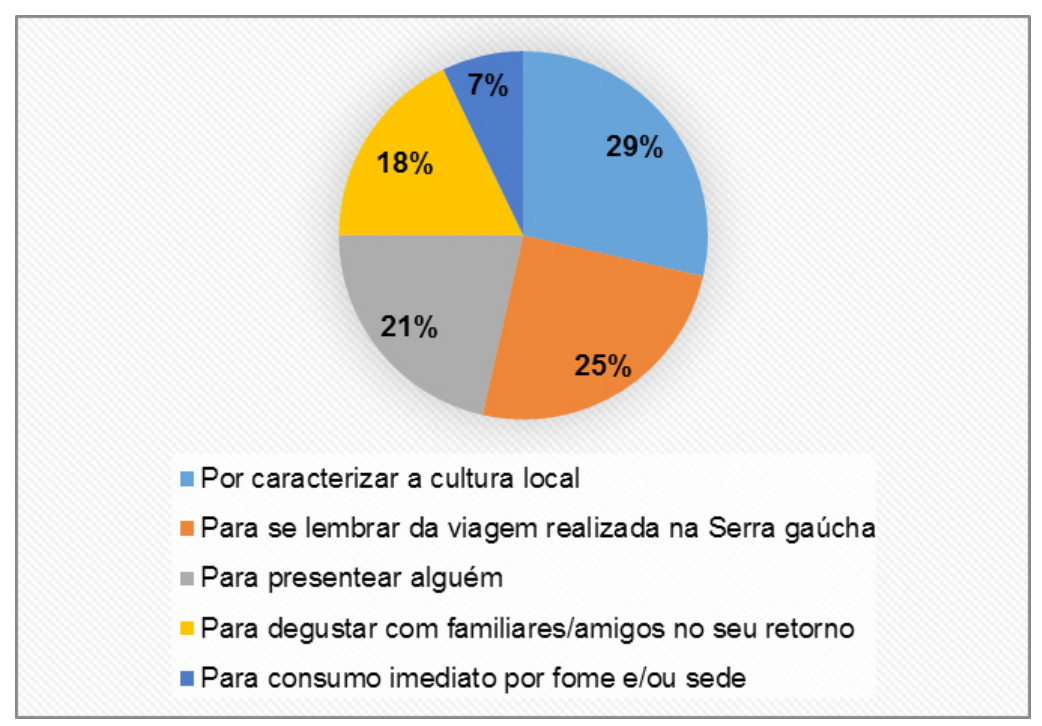

Fonte: Elaboração própria.

Na questão sobre o que o turista espera encontrar no produto à venda na loja de souvenir do passeio de trem "Maria Fumaça", constatou-se que os itens preço acessivel e rótulo/marca e que ajudem a reconhecer o local foram os mais citados. Logo, veio a preocupação de que o produto esteja relacionado ao local, (gráfico 3). Nota-se que o preço acessível continua tendo relevância na hora da escolha do produto, confirmando comentários de autores que afirmam que o mesmo deve ter um valor monetário menor (GASTAL, 2004; ESCALONA, 2006). A atenção com o rótulo/marca demonstra que o turista quer comprar um souvenir que seja fabricado no local, pois assim o produto virá com logotipos, escritas, mapas, entre outras informações, que possibilitarão situá-lo na região e evocar a experiência turística. A relação do souvenir com o local onde o turista está no momento vai ao encontro da questão anterior, já que se a produção do mesmo for concretizada pela comunidade local, terá maior relação com a sua cultura. 
Gráfico 3 - O que você espera encontrar no produto à venda neste local

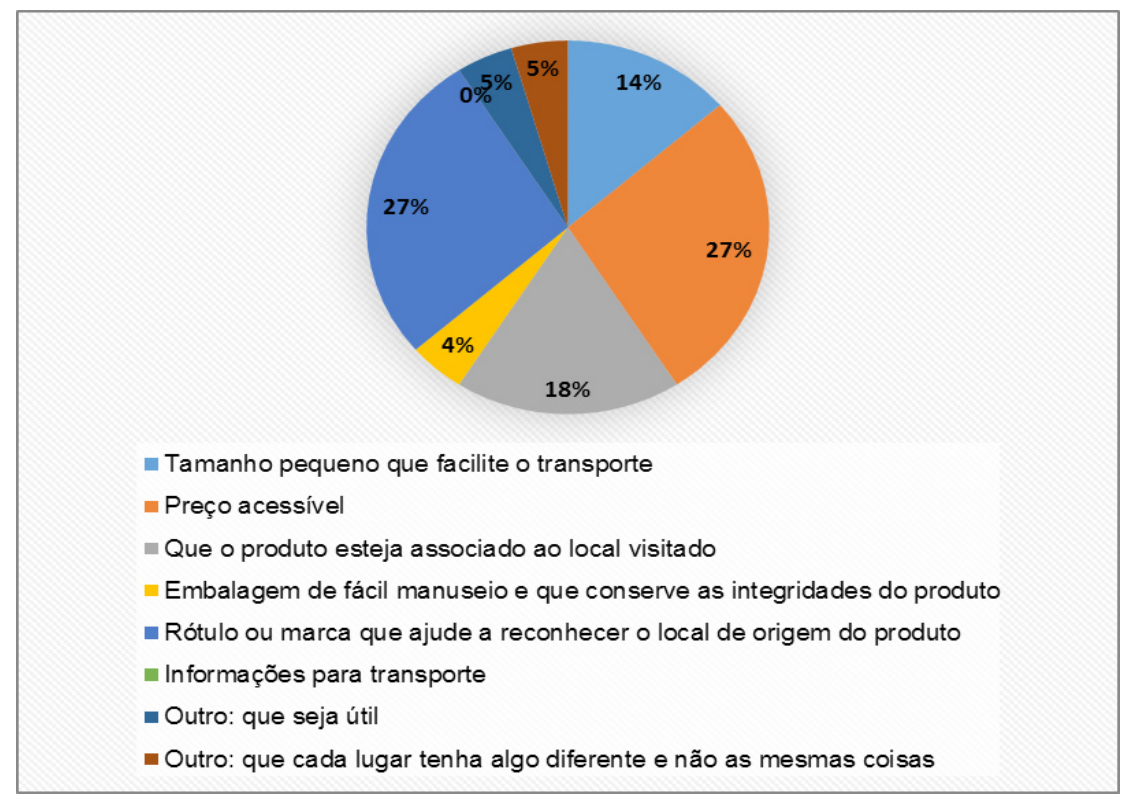

Fonte: Elaboração própria.

Também foi perguntado o que o turista considerou a respeito do produto comprado. A resposta mais elencada pelos turistas foi que o produto tem a capacidade de fazê-los lembrar da viagem à Serra Gaúcha, como pode ser observada no gráfico 4. Assim, essa questão afirma o que foi evidenciado no gráfico 2, tendo em vista que um dos motivos da compra do souvenir era para se lembrar da viagem e, conforme as respostas, os produtos vendidos na loja de souvenir da estação do passeio de trem "Maria Fumaça" conseguem cumprir esse objetivo.

Gráfico 4 - Considerações do turista sobre o produto comprado

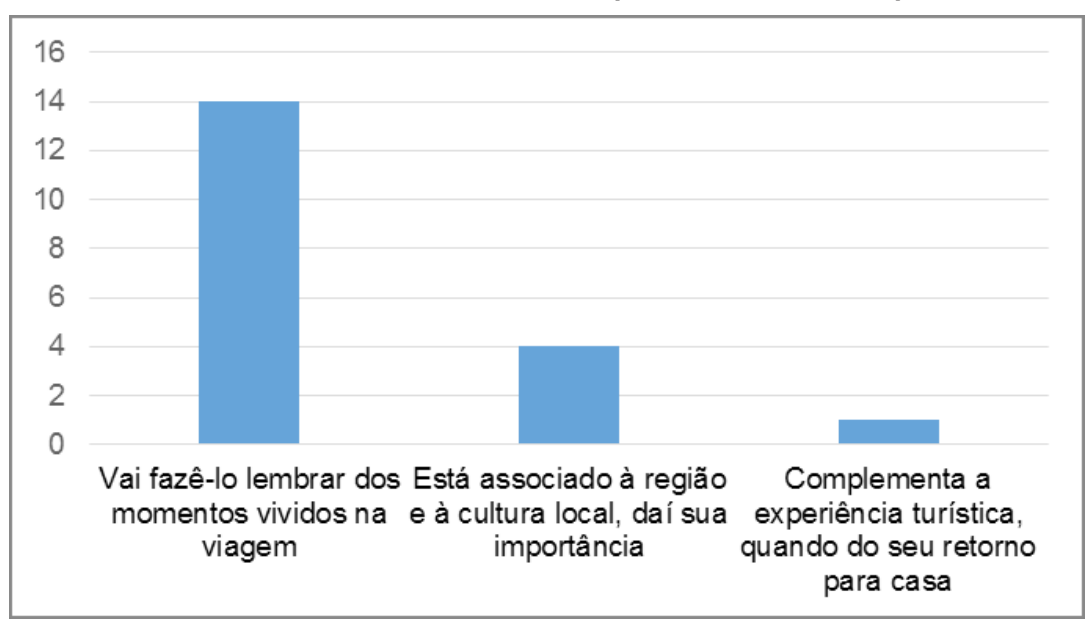

Fonte: Elaboração própria. 
Sobre os produtos comprados, o vinho teve grande destaque. Isto pode estar relacionado à cultura da produção de vinho típica da imigração italiana, aos seus exemplares premiados mundialmente e também por esta bebida ser servida no momento do passeio de trem, o que ocasiona interesse ao consumo. Salienta-se que as respostas não foram agrupadas por categorias, com o intuito de identificar o que realmente foi comprado. Alguns turistas não especificaram o que foi adquirido, colocando, por exemplo, bebidas. Porém, outros foram mais precisos citando, por exemplo, suco de uva. Diante disso, foram mantidas as duas formas de respostas, como pode ser visualizado no gráfico 5.

Gráfico 5 - Produtos comprados pelos turistas

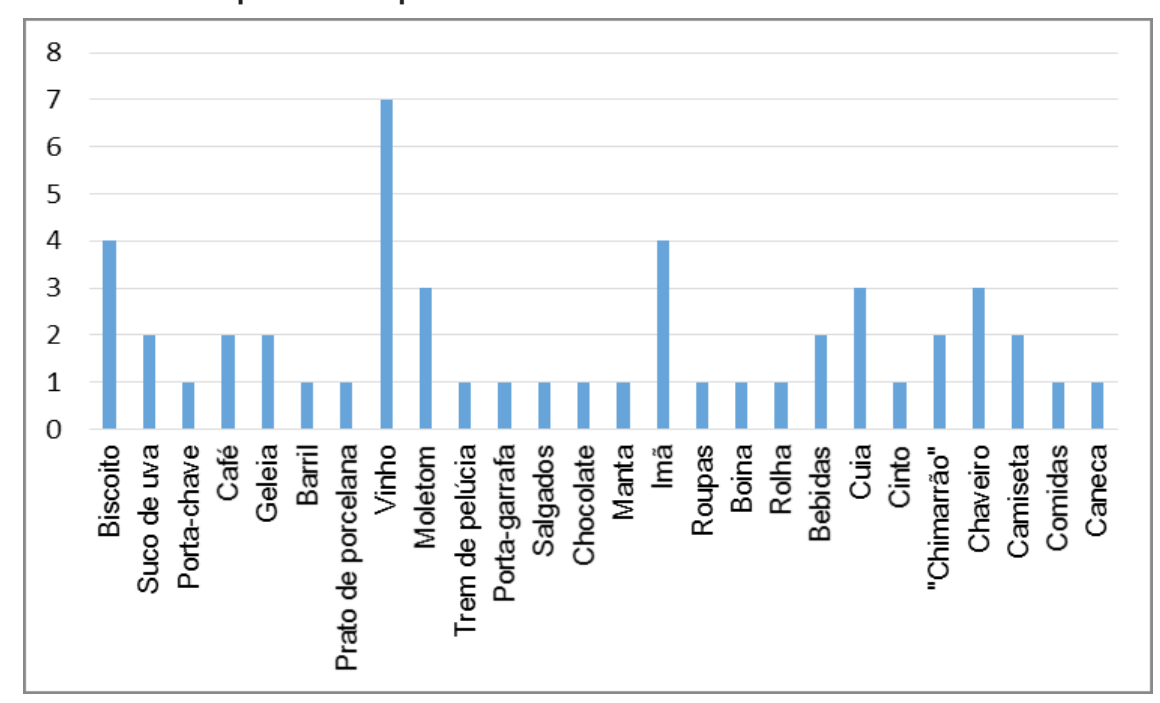

Fonte: Elaboração própria.

A última pergunta do questionário versava sobre quanto o turista investiu, na compra de souvenirs. Contrapondo o gráfico 3, que mostra o preço acessível como uma das variáveis mais escolhidas pelos turistas, esta última indagação revela que a maioria dos respondentes assinalou que gastou mais de $R \$ 60,00$ em suas compras (gráfico 6). Será então que o turista realmente considera o valor monetário como um fator-chave no momento da compra? Sobre esse questionamento pode-se realizar um paralelo com o produto mais comprado, o vinho. Haja vista que, entre as marcas disponíveis no local da pesquisa, o custo médio dessa bebida é de $R \$ 45,00$, pressupõe-se, assim, que este turista prefere produtos que digam algo sobre a região, não priorizando tanto o preço, como no caso do vinho. 
Gráfico 6 - Gasto total na compra de souvenirs

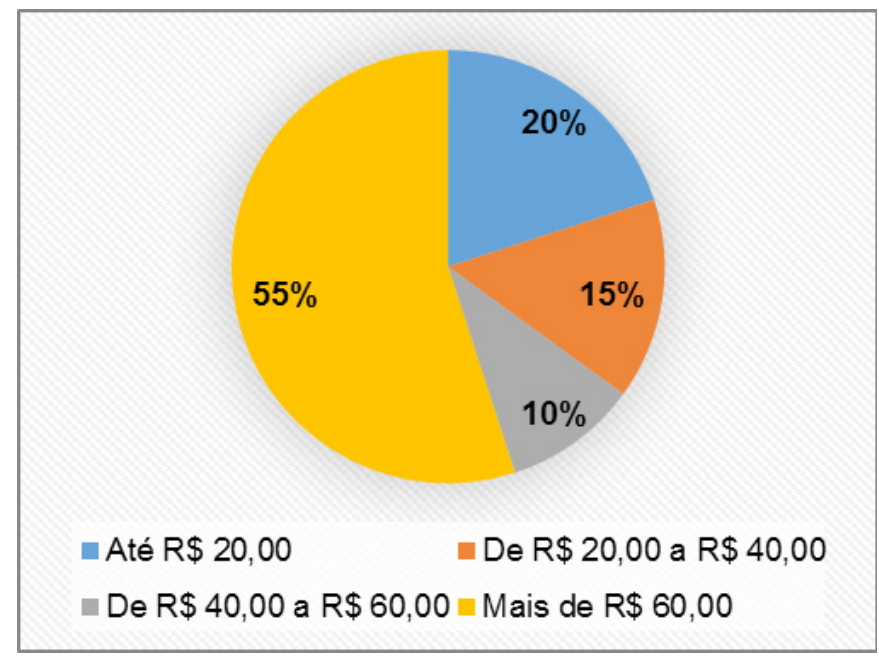

Fonte: elaboração própria.

Realizando um cruzamento dos dados, a partir do souvenir mais comprado, o vinho, constatou-se que, apesar do público predominante na pesquisa ser o feminino, neste caso, a maior parte dos turistas que compraram esse produto é do gênero masculino. A faixa etária que se destacou continua sendo a de jovens de 20 a 30 anos. Nota-se que, no âmbito da escolaridade, esse público possui instrução maior, tendo dois respondentes com doutorado e dois com especialização lato sensu, o que ocasiona senso crítico mais apurado na hora da compra dos produtos. A renda também foi um item que teve seu resultado repetido, dois a dez salários- mínimos. A origem dos turistas foi outro fator que apresentou os mesmos dados, predominando os turistas gaúchos. Sobre qual motivo fez os turistas comprarem o souvenir, as respostas que se destacaram foram por este produto caracterizar a cultura da região, para se lembrar da viagem realizada à Serra Gaúcha e para presentear alguém, corroborando as teorias. No que diz respeito àquilo que o turista esperava encontrar no produto comercializado nesse local, o item mais considerado foi que o souvenir tenha rótulo ou marca que ajude a reconhecer o local de origem do produto, confirmando a importância de o souvenir ser elaborado no local ao qual se refere. Após a compra, o turista considerou que este souvenir vai fazê-lo lembrar dos momentos vividos na viagem; segundo as teorias apresentadas, esta característica é inerente ao souvenir. Por fim, o investimento na compra do souvenir foi maior que $\mathrm{R} \$ 60,00$, ratificando a análise geral da pesquisa. 
Com relação aos itens que ficaram em segundo lugar na preferência dos turistas, as análises, no caso do biscoito, dizem que o turista comprou este souvenir para degustar com familiares e amigos no seu retorno; salientam que o turista esperava encontrar um rótulo com características da região; destacam que o produto comprado era importante porque caracterizava a cultura local e iria auxiliá-los a relembrar os momentos vivenciados na viagem; e continuaram apontando um gasto elevado na compra dos produtos.

Salienta-se a importância do souvenir gastronômico nesta pesquisa, tendo em vista os dois itens mais citados. Para Gordon (1986), os itens alimentícios que representam uma destinação turística são considerados souvenirs. Vários locais possuem souvenirs gastronômicos, que atraem o turista seja por seus ingredientes ou modos de preparo. Schlüter e Ellul (2008, p. 251) trazem como exemplo os alfajores da Argentina e comentam que eles fazem parte da "indústria da recordação". No Brasil, a ampla diversidade cultural possibilita a identificação de vários exemplos de alimentos e bebidas que representam determinada região, como os vinhos da Serra Gaúcha, que possibilitam ao turista uma experiência local que inclui visitação à vinícola e degustação, podendo "levar para casa" essa experiência expressa em uma garrafa de vinho. Outro produto que está cada vez mais sofisticado e caracteriza-se como um souvenir é a cachaça brasileira (PAULA; MECCA; GASTAL, 2015, p. 8).

Ressalta-se que, em pesquisa anterior realizada em Curitiba/PR, também se constatou um item alimentício, a bolacha, como o mais citado no questionamento sobre os souvenirs consumidos (HORODYSKI; MANOSSO; GÂNDARA, 2012). Com isso, verifica-se que produtos alimentícios despertam o interesse dos turistas na hora de adquirir um souvenir.

Quanto ao ímã, percebeu-se que a renda dos turistas que compraram este item era menor, até dois salários-mínimos ( $R \$ 1.576,00)$. O motivo da compra deste souvenir estava relacionado à sua conexão com a cultura regional. Estes turistas esperavam encontrar nos produtos vendidos no local um preço acessível. E o investimento direcionado à compra destes objetos foi de até $R \$$ 20,00, menor do que o constatado na análise global da pesquisa. Verifica-se, então, que a questão da escolha por um produto com valor monetário menor está associada especificamente ao ímã. 
Esta pesquisa cumpriu seu objetivo, pois indicou nuanças do que o turista do passeio de trem "Maria Fumaça" - estação de Bento Gonçalves/RS - percebe sobre o souvenir, gerando dados que possibilitaram a comparação com a teoria e que oportunizarão a ampliação desta pesquisa, incluindo mais turistas, o que evidenciará, assim, o perfil deste na compra desses produtos. Este estudo, portanto, não teve a intenção de representar todo o universo, e sim uma pequena amostra, que indicou algumas características do turista-consumidor do souvenir, pautando-se, então, por uma análise qualitativa.

Constatou-se que os produtos vendidos neste local conseguem conquistar o turista por contemplarem características locais que irão fazê-lo recordar dos momentos vividos na Serra Gaúcha, confirmando as características do souvenir propostas pelos teóricos estudados.

Levando em conta os aspectos contemporâneos mencionados, nota-se que, em contraponto às evoluções tecnológicas oriundas desse período, a vontade de conhecer a cultura local por meio de seus saberes e fazeres é uma característica que também está atrelada à contemporaneidade. Urry (2001, p. 131) corrobora esta questão dizendo que "[...] a nostálgica atração exercida pela 'tradição' pode ser vista como elemento da pós-modernidade".

Em relação ao produto mais comprado, observa-se o interesse pelo vinho que, para a região, é um representante nato da cultura trazida pelos imigrantes italianos. Essa bebida pode ser considerada um símbolo deste território, tendo em vista que, em alguns processos de sua elaboração, ainda é possível encontrar características oriundas dos antepassados. Dessa forma, destaca-se o interesse por souvenirs gastronômicos, tendo em vista o ranking dos produtos comprados o qual enfatizou o vinho e o biscoito.

A maior desmitificação que esta pesquisa apresentou foi em relação ao valor monetário gasto pelos turistas na compra de souvenir. Como evidenciado, a maioria dos turistas gastou um valor considerável nos produtos. Isso pode ser associado ao perfil de turista identificado, que, por suas características, pode 
apresentar um senso crítico maior, definindo suas compras pelo que o souvenir significa dentro do contexto da viagem e não pelo seu valor monetário. Identificou-se que as respostas que apontavam a preferência por elementos de baixo valor monetário estavam relacionadas ao ímã.

Este estudo mostrou que o souvenir artesanal tem espaço garantido no turismo contemporâneo, pois o turista quer levar para casa um pouco das crenças, dos costumes, dos valores e dos hábitos adotados pela comunidade na qual está vivenciando o turismo. Salienta-se que essa comercialização propicia desenvolvimento sustentável para a região pelas oportunidades de emprego, renda e qualificação advindas da produção artesanal do souvenir, além da valorização cultural e da preservação ambiental.

Por fim, sugere-se que este modelo de pesquisa seja replicado em outros destinos turísticos, com o intuito de fortalecer os laços entre o souvenir e o turista, para que, dessa forma, esse elemento tão característico do turismo perca o conceito pejorativo atribuído por algumas teorias.

\section{REFERÊNCIAS}

BARROS, Aidil Jesus da Silveira; LEHFELD, Neide Aparecida de Souza. Fundamentos de metodologia científica. 3. ed. São Paulo: Pearson Prentice Hall, 2007.

CONFEDERAÇÃO NACIONAL DE TURISMO - CNTUR. Serviço brasileiro de apoio às micro e pequenas empresas - SEBRAE. Perfil dos turistas e dos segmentos de oferta. Disponível em: <http://www.sebrae2014.com.br/Sebrae/Sebrae\%202014/Estudos\%20e\%20Pesquisas/ CNTUR\%20Pesquisa\%20de\%20mercado\%20final\%20(2).pdf>. Acesso em: 24 ago. 2015.

DEBENETTI, Valdete Elza Spindler. Passeio de trem Maria Fumaça: os diferentes olhares. 2006. 149 f. Dissertação (Mestrado em Turismo) - Programa de Pós-Graduação em Turismo. Universidade de Caxias do Sul (UCS), 2006.

ESCALONA, Emilia García. De la relíquia al souvenir. Revista de Filología Románica, Madrid, anexo 4, p. 399-408, 2006.

FREIRE-MEDEIROS, Bianca; CASTRO, Celso. A cidade e seus souvenires: o Rio de Janeiro para o turista ter. Revista Brasileira de Pesquisa em Turismo, São Paulo, v.1, n. 1, p. 34-53, 2008. 
GAETA, Cecília. Turismo de experiência e novas demandas de formação profissional. In: PANOSSO NETTO, Alexandre; GAETA, Cecília (Org.). Turismo de experiência. São Paulo: Senac, 2010.

GASTAL, Susana. O tempo na tessitura pós-moderna: entre o museu-acontecimento e o souvenir-memória. In: CONGRESSO BRASILEIRO DE CIÊNCIAS DA COMUNICAÇÃO, 27. 2004, Porto Alegre. Anais eletrônicos... Porto Alegre: Intercom, 2004. Disponível em: <http://www.portcom.intercom.org.br/pdfs/8248547561607761616371556759734274070 8.pdf>. Acesso em: 26 out. 2015.

GASTAL, Susana. Turismo, imagens e imaginários. São Paulo: Aleph, 2005.

GIL, Antônio Carlos. Como elaborar projetos de pesquisa. São Paulo: Atlas, 2007.

GRUPO GIORDANI TURISMO. Locomotiva “Maria Fumaça". Disponível em: < http:// giordaniturismo.tempsite.ws/mfumaca/default.html>. Acesso em: 26 out. 2015.

GORDON, Beverly. The souvenir: messenger of the extraordinary. Journal of Popular Culture, [S.I.], v. 20, n. 3, p. 135-146, 1986.

HORODYSKI, Graziela Scalise; MANOSSO, Franciele Cristina; GÂNDARA, José Manoel Gonçalves. O consumo de souvenirs e a experiência turística em Curitiba (PR). Caderno Virtual de Turismo, Rio de Janeiro, v. 12, n. 3, p. 323-342, 2012.

KÖCHE, José Carlos. Fundamentos de metodologia científica: teoria da ciência e iniciação à pesquisa. Petrópolis/RJ: Vozes, 2013.

KOTLER, Philip; ARMSTRONG, Gary. Princípios de marketing. São Paulo: Pearson Prentice Hall, 2007.

KRUCKEN, Lia. Design e território: valorização de identidades e produtos locais. São Paulo: Studio Nobel, 2009.

MACHADO, Paula de Souza; SIQUEIRA, Euler David. Turismo, consumo e cultura: significados e usos sociais do suvenir em Petrópolis-RJ. Contemporânea, v. 10, n. 1, p. 2-18, 2008.

MASCARANHAS, Sidnei Augusto. Metodologia científica. São Paulo: Pearson Education do Brasil, 2012.

MELO, Mariana Inocêncio Oliveira; DIAS, Karina Silva. Parque Farroupilha, a natureza na cidade: práticas de lazer e turismo cidadão. Revista de Turismo Contemporâneo - RTC, v. 2, n. 1, p. 1-26, jan./jun. 2014.

MELLO, Carolina Luva; CERETTA, Caroline Ciliane. El souvenir artesanal y la promoción de la imagen del lugar turístico. Estudios y Perspectivas en Turismo, v. 24, n. 2, p. 188-204, 2015. 
MICHEL, Maria Helena. Metodologia e pesquisa científica em ciências sociais. São Paulo: Atlas, 2005.

MINAYO, Maria Cecília de Souza; ASSIS, Simone Gonçalves; SOUZA, Edinilsa Ramos de. Avaliação por triangulação de métodos: abordagem de programas sociais. Rio de Janeiro: Fiocruz, 2005.

NORRILD, Juana. El mate como souvenir turístico em Argentina: su identidad funcional y ornamental. In: COMISIÓN PARA LA PRESERVACIÓN DEL PATRIMONIO HISTÓRICO CULTURAL DE LA CIUDAD DE BUENOS AIRES. La artesanía urbana como patrimônio cultural. Buenos Aires, 2004.

PAULA, Tauana Macedo de; MECCA, Marlei Salete. A relação do souvenir com a economia criativa: um estudo de caso. In: BEM, Judite Sanson de. As aglomerações industriais do Rio Grande do Sul. Caxias do Sul: Educs, 2015.

PAULA, Tauana Macedo de; MECCA, Marlei Salete; GASTAL, Susana. Interfaces entre as características da economia criativa brasileira e a produção do souvenir gastronômico. In: SEMINÁRIO DA ASSOCIAÇÃO NACIONAL DE PESQUISA E PÓS-GRADUAÇÃO EM TURISMO (Anptur), 12., 2015, Natal. Anais eletrônicos... Natal: Anptur, 2015.

PANOSSO NETTO, Alexandre. O que é turismo. São Paulo: Brasiliense, 2013.

PREFEITURA MUNICIPAL DE BENTO GONÇALVES. Disponível em: <www.bentogoncalves. rs.gov.br/>. Acesso em: 15 set. 2015.

REIS, Jarlene Rodrigues. "Lembrei-me de você": o consumo de souvenires atribuindo significado à viagem turística. In: SEMINÁRIO DA ASSOCIAÇÃO NACIONAL DE PESQUISA E PÓS-GRADUAÇÃO EM TURISMO (Anptur), 5., 2008, Belo Horizonte. Anais eletrônicos... Belo Horizonte: ANPTUR, 2008.

RUBIO, Saida Palou. Reseña de 'trofei di viaggio. per un'antropologia dei souvenir" de Canestrini, Duccio. Pasos Revista de Turismo y Patrimonio Cultural, Santa Cruz de Tenerife, v. 4, n. 2, p. 279-285, 2006.

SALGUEIRO, Valéria. Grand tour: uma contribuição à história do viajar por prazer e por amor à cultura. Revista Brasileira de História, São Paulo, v. 22, n. 44, p. 289-310, 2002.

SCHLÜTER, Regina. The role t-shirts in the creation of tourist destination images. Estudios y Perspectivas en Turismo, Buenos Aires, v.7, p. 5-23, 1998.

SCHLÜTER, Regina; ELLUL, Daniela Thiel. Gastronomía y turismo en Argentina: polo 
gastronómico Tomás Jofré. Pasos Revista de Turismo y Patrimonio Cultural, Santa Cruz de Tenerife, v. 6, n. 2, p. 249-268, 2008.

SMITH, Valene L. Hosts and guests: the anthropology of tourism. Philadelphia/ Pennsylvania: University of Pennsylvania Press, 1989.

SOUZA, Amanda Moreira; CARVALHO, Alissandra Nazareth. O comércio de souvenires e sua relação com a imagem da destinação: um estudo na cidade de Itu/SP. Revista Hospitalidade, v. 11, n. 1, p. 64-89, 2014.

SWANSON, Kristen. Tourists and retailers perceptions of souvenirs. Journal of Vacation Marketing, [S.I.], v. 10, n. 4, p. 363-377, 2004.

SWANSON, Kristen; HORRIDGE, Patrícia. A structural model for souvenir consumption, travel activities, and tourist demographics. Journal of Travel Research, [S.I.], v. 42, n. 4, p. 372-380, 2004.

SWANSON, Kristen; TIMOTHY, Dallen. Souvenirs: icons of meaning, commercialization and commoditization. Tourism Management, [S.I.], v. 33, p. 489-499, 2012.

URRY, John. O olhar do turista: lazer e viagens nas sociedades contemporâneas. 3. ed. São Paulo: Studio Nobel, 2001. 